\title{
PERANCANGAN ALAT PENGOLAHAN AIR MINUM OTOMATIS PADA PROSES NETRALISASI Ph DAN AERASI
}

\author{
Agung Satria Alam ${ }^{1}$, Hendi Matalata ${ }^{2}$ \\ ${ }^{1}$ Jurusan Teknik Listrik, Fakultas Teknik, Universitas Batanghari \\ ${ }^{2}$ Dosen Teknik Listik, Fakultas Teknik, Universitas Batanghari \\ e-mail : agungsatria344@gmail.com \\ e-mail : hendi.matalata@unbari.ac.id
}

\begin{abstract}
ABSTRAK
Air merupakan kebutuhan pokok bagi kehidupan manusia dalam kehidupan sehari-hari terutama untuk minum, masak, mandi dan mencuci. dalam upaya penyediaan air bersih dan sehat bagi masyarakat pedesaan yang mana kualitas air tanahnya buruk serta belum mendapatkan pelayanan air minum dari PAM, oleh karena itu masyarakat perlu membuat alat pengolahan air minum sederhana yang murah dan dapat dibuat oleh masyarakat dengan bahan yang ada dipasaran. Kebutuhan akan teknologi untuk pengontrolan sirkulasi air berperan penting dalam pengolahan air bersih dimana pada prosesnya diharapakan dapat bekerja secara otomatis, peran penting otomatis ini sangat berguna selain memudahkan untuk pengolahan air bersih dan tentunya dapat juga menghasilkan air bersih yang lebih efektif, pada penelitian ini dilakukan sebuah perancangan alat proses aerasi dan netralisasi $\mathrm{pH}$ dengan menggunakan komponen analog dimana proses kerja yang di lakukan dapat mengatur proses pengandukan air, proses pengendapan dan bukak tutup valpe atau keran otomatis di atur berdasarkan waktu yang di seting dari sirkulasi air.dari hasil pengujian di dapat unjuk kerja perancangan alat sesuai dengan yang di harapkan, namun demikian pada penelitian dini tidak mengukur kadar dan $\mathrm{pH}$ air tetapi hanya proses kontrol secara elektrikal.
\end{abstract}

Kata kunci: alat pengolahan, air minum, prose netralisasi Ph dan aerasi

\section{PENDAHULUAN}

Air gambut di beberapa lokasi bervariasi, tergantung struktur tanahnya, umur gambut, kedalaman serta tumbuhan yang hidup diatasnya.

Sumur didaerah bergambut atau daerah rawa pada umumnya dangkal dengan air berwarna cokelat, berkadar asam humus, zat organik dan besi yang tinggi. Salah satu alat pengolah air minum sederhana untuk mengolah air gambut terdiri dari merupakan rangkaian proses netralisasi, aerasi, kougalasi-flokoulasi, sedimentasi dan filtrasi. Peralatan dari Tangki, pengaduk, pompa aerasi dan saringan dari pasir, alat ini dirancang untuk keperluan rumah tangga sedemikian rupa sehingga cara pembuatan dan cara pengoperasiannya mudah serta biayanya murah. Kebutuhan akan teknologi untuk pengontrolan sirkulasi air berperan penting dalam pengolahan air bersih dimana pada prosesnya diharapakan dapat bekerja secara otomatis, peran penting otomatis ini sangat berguna selain memudahkan untuk pengolahan air bersih dan tentunya dapat juga menghasilkan air bersih yang lebih efektif, sistem otomatis ini melalui proses kontrol menggunakan perangkat-perangkat elektrikal seperti PLC, Mikrokontroller atau rangkaian analog.

Proses kontrol menggunakan PLC atau Mikrokontroller memiliki rangkaian yang lebih sederhana dibandingkan dengan rangkaian analog yang tentunya lebih kompleks pada sistem perakitan namun lebih mudah dalam perbaikan, pada penelitian ini penulis akan merancang sistem kontrol untuk pengaturan sistem penjernihan air dimulai dari netralisasi $\mathrm{Ph}$ sampai proses aerasi, dimana pada prosesnya dilakukan pengadukan air mengunakan putaran motor bekerja secara 
otomatis, pemompaan, pemberian oksigen dan buka tutup valve saluran air berdasarkan sirkulasi air.

\section{TINJAUAN PUSTAKA}

\subsection{Proses Pengolahan}

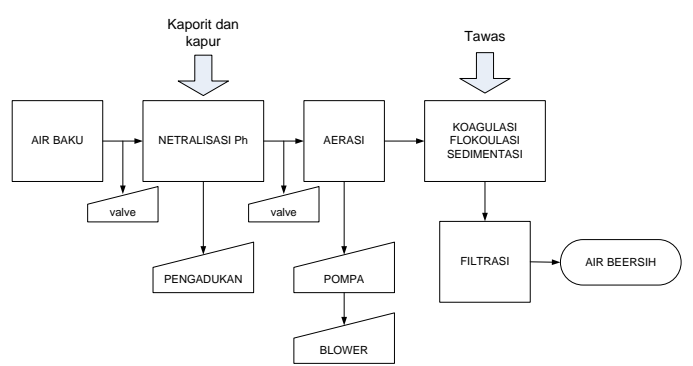

Gambar 1. Proses Pengolahan Air Sederhana

\subsection{Selenoid Valve}

Untuk membuka dan menutup saluran air dari wadah penampungan air ke wadah penampungan air lain dibutuhkan kran otomatis yang mana kran ini akan bekerja bila mendapat catu daya listrik / tegangan (volt), salah satu indikator teknis utama dari selenoid valve adalah:

1. Penggunaan lingkungan bukan ketinggian lebih dari 2500 meter; 106Kpa tekanan atmosfir 86;

2. Suhu lingkungan $+1 \mathrm{C} \sim+45 \mathrm{C}$; suhu air adalah $0 \mathrm{C} \sim+60 \mathrm{C}$; suhu penyimpanan dan transportasi - $30 \sim$ 60C;

3. Kelas perlindungan IP00; kelembaban relatif $<=95 \%$;

4. Nilai tegangan kerja, DC12V (deteksi jatuh tegangan $15 \%$ ), Peringkat daya, 4W- 5W, Nilai arus operasi 0,42 A, Tekanan Operasi: $0,02 \sim 0.8 \mathrm{MP}$ dan dapat menahan tekanan statis tidak kurang dari $1.6 \mathrm{Mpa}$

Adapun bentuk fisik dari salah satu selenoid valve DC ditunjukan pada gambar 2 dibawah.

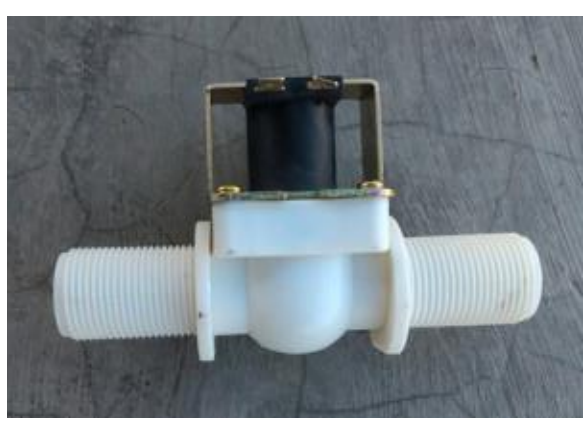

Gambar 2. Bentuk Fisik Selenoid Valve DC

\subsection{Proses Netralisasi}

Pada proses netralisasi adalah untuk mengatur keasaman air agar menjadi netral (pH 7-8). Untuk air yang bersifat asam misalnya air gambut, yang paling murah dan mudah adalah dengan pemberian kapur/gamping. Fungsi dari pemberian kapur, disamping untuk menetralkan air baku juga untuk membantu efektifitas proses selanjutnya. Pada proses ini dibutuhkan motor DC sebagai pengaduk dimana dibutuhkan pengaturan waktu untuk kecepatan putaran, topologi sederhana pada pengaturan waktu kecepatan putaran motor DC adalah dengan mengunakan rangkaian oscilator, dimana gelombang sinyal yang dibangkitkan berbentuk gelombang kotak (square wave) dengan besar amplitudo yang konstan. Adapun bentuk dari gelombang kotak seperti ditunjukan pada gambar 3 dibawah.

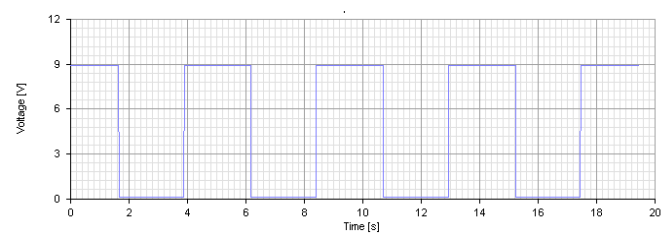

Gambar 3. Bentuk Gelombang Kotak

Salah satu cara untuk pembangkitan gelombang kotak adalah dengan menggunakan IC NE 555, bentuk fisik dari IC tersebut diperlihatkan pada gambar 4 dibawah. 


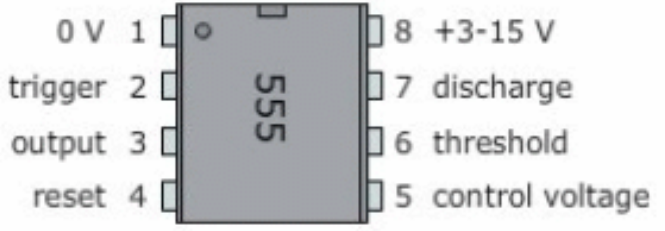

Gambar 4. Bentuk Fisik IC NE 555

\subsection{Proses Aerasi}

Yaitu mengontakkan udara dengan air baku agar kandungan zat besi dan mangan yang ada dalam air baku bereaksi dengan oksigen yang ada dalam udara membentuk senyawa besi dan senyawa mangan yang dapat diendapkan. Secara teoritis dapat dihitung bahwa untuk $1 \mathrm{ppm}$ oksigen dapat mengoksidasi $6,98 \mathrm{ppm}$ ion besi. Jadi makin merata dan makin kecil gelembung udara yang dihembuskan kedalam air bakunya, maka oksigen yang bereaksi makin besar, pada proses ini dibutuhkan motor pompa DC dan motor blower DC yang mana masing-masing motor bekerja untuk mensirkulasi air dan memberikan oksigen kedalam air. Simbol dan Bentuk dari motor DC seperti ditunjukan gambar 5 dibawah.

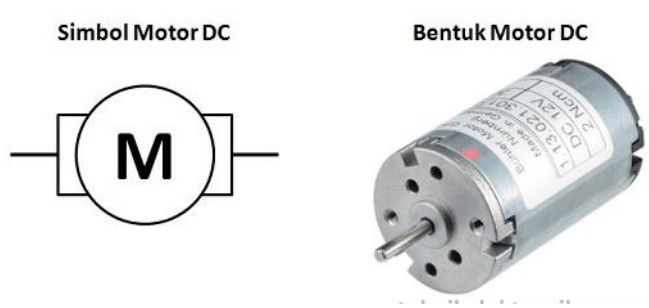

Gambar 5. Simbol dan Bentuk Motor DC

Motor Listrik DC tersedia dalam berbagai ukuran rpm dan bentuk. Kebanyakan Motor Listrik DC memberikan kecepatan rotasi sekitar $3000 \mathrm{rpm}$ hingga $8000 \mathrm{rpm}$ dengan tegangan operasional dari $1,5 \mathrm{~V}$ hingga $24 \mathrm{~V}$. Apabile tegangan yang diberikan ke Motor Listrik DC lebih rendah dari tegangan operasionalnya maka akan dapat memperlambat rotasi motor DC tersebut sedangkan tegangan yang lebih tinggi dari tegangan operasional akan membuat rotasi motor DC menjadi lebih cepat. Namun ketika tegangan yang diberikan ke Motor DC tersebut turun menjadi dibawah $50 \%$ dari tegangan operasional yang ditentukan maka Motor DC tersebut tidak dapat berputar atau terhenti. Sebaliknya, jika tegangan yang diberikan ke Motor DC tersebut lebih tinggi sekitar 30\% dari tegangan operasional yang ditentukan, maka motor DC tersebut akan menjadi sangat panas dan akhirnya akan menjadi rusak.

\section{METODE PENELITIAN}

\subsection{Perancangan Alat}

Ada beberapa tahap dalam perancangan alat yang dilakukan, tahapantahapan tersebtu diperlihatkan pada gambar

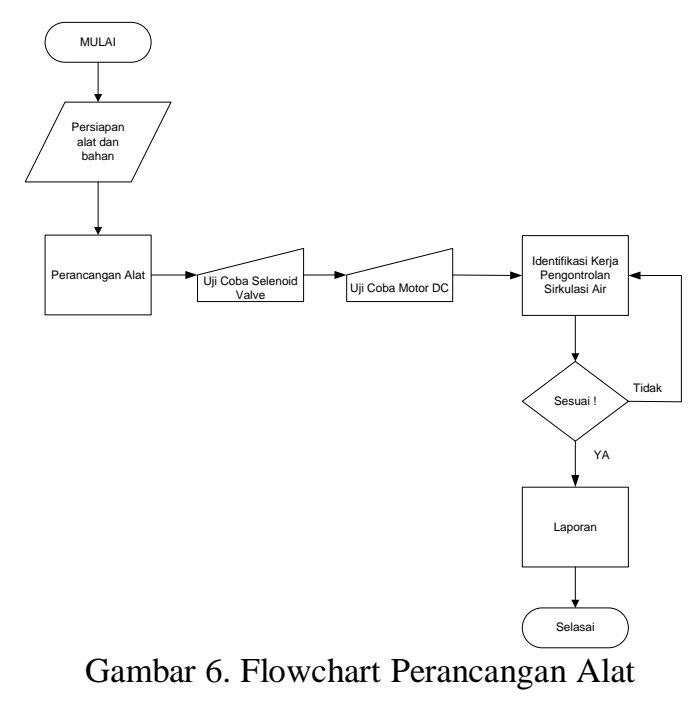

\subsection{Persiapan Alat dan Bahan}

Pada persiapan ini, dilakukan analisa kebutuhan utama alat dan bahan yang digunakan untuk mendapatkan hasil yang diinginkan. Kebutuhan itu mencakup sistem elektrikal pengontrolan sirkulasi air pada proses netralisasi $\mathrm{Ph}$ dan aerasi seperti selenoid valve, motor pompa DC, blower, motor DC, rangkaian Oscilator, Timer dan catu daya.

\subsection{Perancangan Alat}

Setelah alat dan bahan yang dibutuhkan didapat maka selanjutnya dilakukan perancangan alat, wiring diagram 
dari perancangan alat seperti gambar berikut:

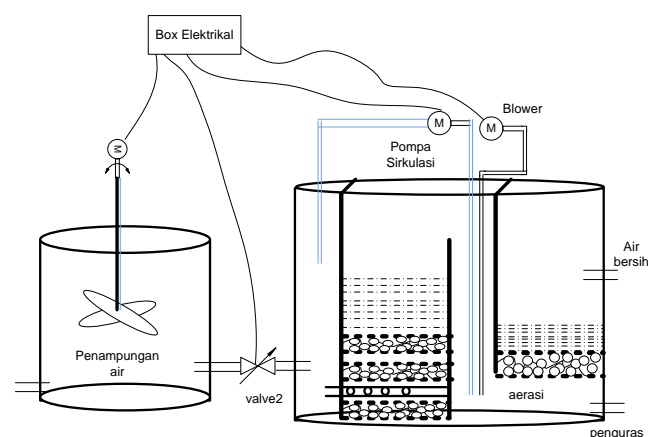

Gambar 7. Model Perancangan Alat

\subsection{Pengujian Alat}

Pada pengujian alat dilakukan unjuk kerja dari masing-masing komponen yang terdapat pada perancangan alat, masingmasing dari hasil pengujian adalah:

a. Uji Motor DC

Pengujian Motor DC ini dilakukan untuk memutar / pengaduk air pada bak penampungan, pengadukan ini dilakukan untuk beberapa saat lalu motor akan berhenti untuk proses pengendapan air setelah itu selenoid valve akan membuka untuk proses selanjutnya.

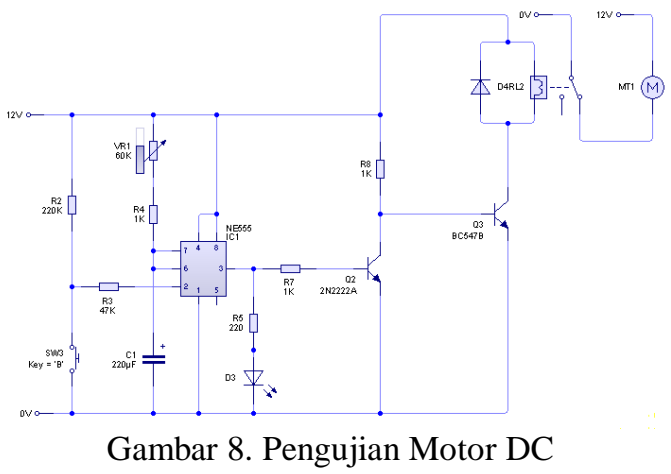

Dari gambar 8 diatas, lama putaran motor berdasarkan besar dari nilai potensio meter (VR1) dan kapasitor (C1) dimana besar dari nilai kapasitor $470 \mathrm{uF}$, berikut hasil pengujian yang dilakukan:

Tabel 1. Pengujian Transistor

\begin{tabular}{cccccc}
\hline \multicolumn{3}{c}{ Transitor } & 2N2222 & \multicolumn{3}{c}{ Transitor BC 547 } \\
$\mathrm{I}_{\mathrm{C}}$ & $\mathrm{I}_{\mathrm{B}}$ & $\mathrm{B}$ & $\mathrm{I}_{\mathrm{C}}$ & $\mathrm{I}_{\mathrm{B}}$ & $\beta$ \\
$(\mathrm{mA})$ & $(\mathrm{mA})$ & & $(\mathrm{mA})$ & $(\mathrm{mA})$ & \\
\hline
\end{tabular}

\begin{tabular}{llllll}
\hline 50 & 1 & 50 & 75 & 37 & 2 \\
\hline
\end{tabular}

Dari tabel 1 diatas, pengujian transistor dilakukan untuk mendapat penguatan dari masing-masing jenis transistor dimana tipe 2N2222 digunakan untuk memberikan umpan arus listrik pada transistor BC 547 agar dapat menggerakan relay.

Tabel 2. Pengujian Motor DC

\begin{tabular}{cc}
\hline $\begin{array}{c}\text { VR1 } \\
(100 K)\end{array}$ & $\begin{array}{c}\text { Lama Putaran } \\
\text { (detik) }\end{array}$ \\
\hline $1 / 3$ putaran & 12 \\
$1 / 2$ putaran & 18 \\
3/4 putaran & 20 \\
$1 \quad$ putaran & 29 \\
\hline
\end{tabular}

b. Uji Selenoid Valve

Pada rancang bangun penelitian ini, selenoid valve digunakan untuk membuka dan menutup saluran air dari bak pengisi air ke bak penampungan air lalu dari bak penampungan air ke bak proses aerasi, proses buka dan tutup selenoid valve dilakukan dengan pengendalian fungsi waktu menggunakan IC timer NE 555 dan pengendalian berdasarkan keadaan air (penuh) menggunakan Transistor sebagai penguat.

\section{IC timer NE 555}

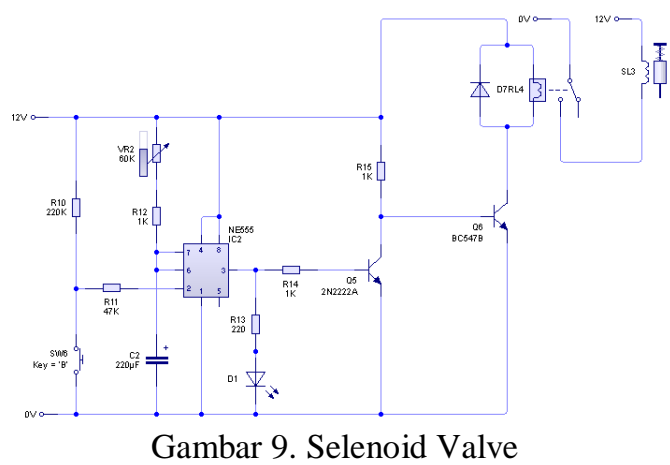

Dari gambar 9 diatas, lama membuka selenoid Valve berdasarkan besar dari nilai potensio meter (VR1) dan kapasitor (C1) dimana besar dari nilai kapasitor $2200 \mathrm{uF}$, berikut hasil pengujian yang dilakukan: 
Tabel 3. Selenoid Valve

\begin{tabular}{lc}
\hline $\begin{array}{c}\text { VR1 } \\
(100 \mathrm{~K})\end{array}$ & $\begin{array}{c}\text { Lama } \\
\text { membuka } \\
\text { (detik) }\end{array}$ \\
\hline 1/3 putaran & 64 \\
1/2 putaran & 81 \\
3/4 putaran & 92 \\
$1 \quad$ putaran & 139 \\
\hline
\end{tabular}

c. Uji Pompa DC

Pengujian Pompa ini dilakukan untuk sirkulasi air pada proses aerasi yang mana pompa akan bekerja bila pada bak proses aerasi berisi(penuh), dan sebaliknya pompa DC akan mati bila bak proses aerasi tidak berisi air.

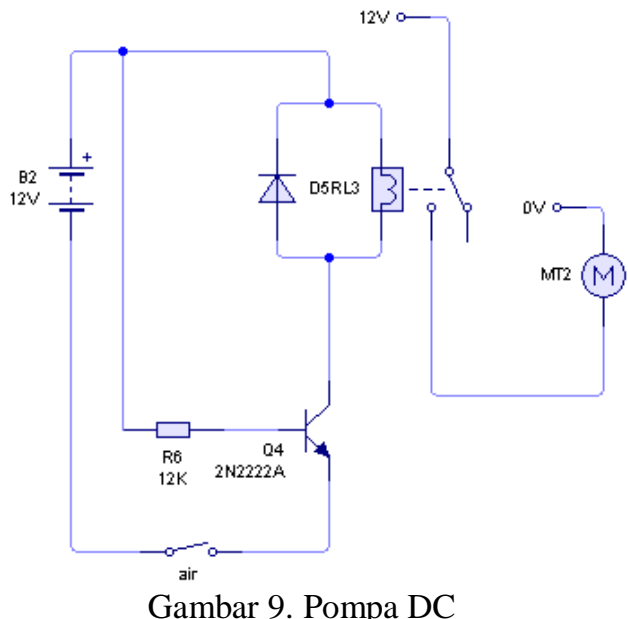

Hasil pengujian dari pompa DC adalah bagaimana transistor digunakan sebagai penguat untuk menggerakan relay sekaligus digunakan sebagai sensor untuk mendeteksi keadaan air, yang mana kaki emitor sebagai penghubung ke catu daya dengan air sebagai media penghantar.

Tabel 4. Pengujian Pompa DC Transitor 2N2222

\begin{tabular}{ccc}
\hline $\mathrm{I}_{\mathrm{C}}(\mathrm{mA})$ & $\begin{array}{c}\mathrm{I}_{\mathrm{B}} \\
(\mathrm{mA})\end{array}$ & $\begin{array}{c}\text { Penguatan } \\
(\beta)\end{array}$ \\
\hline 0,927 & 117 & 126 \\
\hline
\end{tabular}

d. Uji Blower

Pada rancang bangun penelitian ini, blower digunakan untuk memberikan udara pada air di bak aerasi, pengujian yang dilakukan sama seperti pengujian pompa DC, dimana kerja dari blower bersamaan dari kerja motor DC.

\section{HASIL DAN PEMBAHASAN}

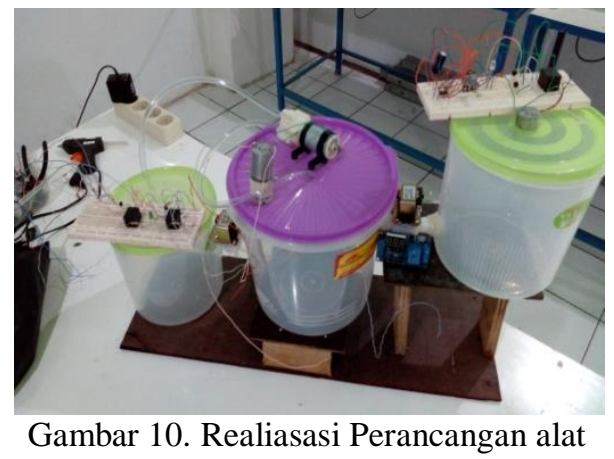

Pada tahap ini dilakukan identifikasi kerja pada rancang bangun keseluruhan alat, dimana hasil yang diharapkan sesui dengan keinginan dari perancangan pada penelitian. Tahapan-tahapan dari hasil yang diinginkan adalah dengan mengasumsikan wadah air pada bak penampungan sebanyak 1,5 liter, air ini yang akan diproses untuk netralisasi $\mathrm{Ph}$ air dan proses aerasi secara automatis menggunakan peralatan kontrol komponen analog. berikut hasil dari unjuk kerja peralatan seperti ditunjukan gambar 10 dibawah.

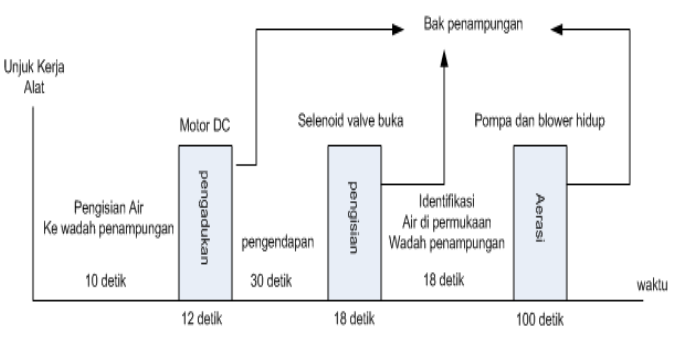

Gambar 11. Unjuk Kerja Peralatan

Penjelasan dari gambar 10 diatas dapat diuraikan sebagai berikut:

a. Pengisian air ke wadah penampungan yang berisi air 1,5 liter selama 10 detik.

b. Setelah air berisi penuh maka selanjutnya motor DC bekerja untuk proses pengadukan, pengaturan pengadukan disetting selama 12 detik. setelah 12 detik motor bekerja maka akan dilakukan proses pengendapan.

c. Pengendapan dilakukan sebagai asumsi proses turunnya campuran-campuran air 
yang terdapat pada proses pengadukan, proses pengendapan ini disetting selama 30 detik, lalu selenoid valve membuka untuk proses pengisian pada bak aerasi.

d. Pada kondisi selenoid valve membuka setting waktu dilakukan berdasarkan pengaliran air pada tinggi muka air dipermukaan bak penampungan proses aerasi yang mana terdapat sensor dengan transistor sebagai penguat, waktu pengaliran air yang dibutuhkan adalah selama 18 detik, lalu selenoid menutup kembali.

e. Bersamaan dengan kondisi selenoid menutup maka pompa dan blower hidup untuk sirkulasi air dan memberikan udara pada air. proses ini disetting selama 100 detik.

\section{SIMPULAN}

a. Perancangan alat yang dilakukan dapat mensetting pengaturan waktu pada proses pengendapan dan pengadukan air pada wadah penampungan sesui dengan besar kapasitas wadah penampungan

b. Penggunaan komponen analog mampu menghasilkan perancangan alat pengontrolan sirkulasi air pada proses penjernihan air secara ekonomis

\section{DAFTAR PUSTAKA}

[1] Dickshon Kho, 2018, Pengertian Relay dan Fungsinya, https://teknikelektronika.com/pengertia n-relay-fungsi-relay/, diakses 12 agustus 2018

[2] Toko Arduino, 2016, Selenoid Valve 1/2 Inch Penutup Aliran Air Otomatis DC12Volt,www.tokoarduino.com/sole noid-valve-12-inch-inchi-12-penutupaliran-air-otomatis-dc-12v-2/, diakses 03 juni 2018

[3] M.Arif.F.A, A.Cahyadi, 2016, Pengembangan Sistem Aerasi Untuk Penurunan Kadar Besi Dalam Air Tanah, Prosiding Seminar Nasional
Geografi Lingkungan I, Fakultas Geografi UGM Yogyakarta, 249-254

[4] Mubarak.A, 2016, Keefektifan Waktu Aerasi Menggunakan Bubble Aerator dalam Menurunkan Kadar Besi(Fe) Air Sumur Desa Kebarongan Kemranjen Banyumas Tahun 2016, Skripsi, Program Studi Kesehatan Masyarakat, Fakultas Ilmu Kesehatan, Universitas Muhammadiyah Surakarta. 